
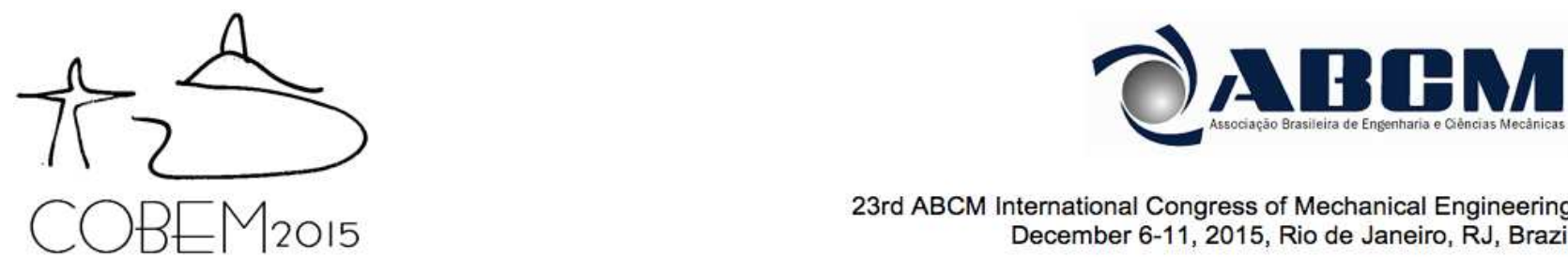

23rd ABCM International Congress of Mechanical Engineering December 6-11, 2015, Rio de Janeiro, RJ, Brazil

\title{
TEMPERATURE EFFECT ON THE STATIC BEHAVIOUR OF ADHESIVELY-BONDED METAL SKIN TO COMPOSITE STIFFENER
}

\author{
Sofia Teixeira de Freitas \\ Jos Sinke \\ Faculty of Aerospace Engineering - Delft University of Technology, Delft, The Netherlands \\ s.teixeiradefreitas@tudelft.nl,j.sinke@tudelft.nl
}

Abstract. The purpose of this research is to study the effect of temperature on the static behavior of an hybrid structure consisting of adhesively bonded Fiber Metal Laminate skin to a composite stiffener. This hybrid structure was tested using stiffener pull-off tests, which is a typical set-up used to simulate the structural behaviour of full-scale components subject to out-of-plane loading. The failure mechanism is very similar at the three temperatures tested: $-55^{\circ} \mathrm{C}$, Room Temperature and $+100^{\circ} \mathrm{C}$. The damage initiates at the central noodle of the composite stiffener. Unstable delamination then propagates from the noodle to the tip of the stiffener foot, preferably through the stiffener foot plies. However, the maximum load and corresponding displacement increase significantly with temperature. At $+100{ }^{\circ} \mathrm{C}$ the maximum load increases approximately $15 \%$ to $30 \%$ when compared to $R T$. At $-55{ }^{\circ} \mathrm{C}$ the maximum load decreases approximately $50 \%$ to $60 \%$ when compared to RT. No influence of the adhesive was observed in the maximum load values, since no damage occurs at the adhesive bondline. This research identifies that the composite stiffener is the weakest link of the hybrid bonded structure metal-skin-to-composite-stiffener and not the adhesive bondline. This holds for static loading in a wide temperature range.

Keywords: Adhesive bonding, skin-to-stiffener connection, composite-to-metal joints, hybrid structures

\section{INTRODUCTION}

Joining is a key technology enabler for the implementation of new materials in structures. In order to fully exploit the capacity of the new composite materials in aircraft structures, suitable joining technologies must be implemented. Adhesive bonding offers major advantages to riveting or welding. Not only in terms of structural performance, since it avoids high stress concentrations, but also the ability to join different materials.

Two of the major points to address when adhesively bonding composite-to-metals are (1) assure that the adhesive used is suitable for both materials and their corresponding surface pre-treatments in order to guarantee a good adhesion at the interfaces and (2) guarantee the structural integrity of the components in a wide temperature range.

The first point has been addressed in previous publications from the authors (Teixeira de Freitas and Sinke, 2014, 2015b). This previous work consisted of selecting the most suitable adhesives to the application based on screening tests on 10 adhesives at different environmental conditions. In addition to this, the previous work introduced a new testing method to assess adhesion strength in composite bonded structures. This new test method is based on floating roller peel tests but adapted to composite adherends. The new tests method is in contrast to what has been observed in other studies up to now, which mainly focus on lap shear tests or double cantilever beams test to study composite-to-metal bonded structures (Seong et al., 2008; Khoshravan and Asgari Mehrabadi, 2012).

For the second point, in order to guarantee the structural integrity of the components, it is necessary to study the performance not only on the coupon level but especially on the sub-component level. In aircraft applications, skin-tostiffener joints are very common in fuselage panels and wings. In order to simulate the performance of those full-scale structures, sub-components tests are performed with representative boundary and load conditions. Stiffener pull-off tests (SPOT) is a common test method used to simulate out-of-plane loading in skin-to-stiffener joints, such as internal pressure of the fuselage skin and low pressure zones of leading edges (Li, 2002).

However, most of the research up to now using SPOT is focused on co-cured composite bonded structures or adhesively bonded metal structures (Greenhalgh et al., 2006). No significant research has been done in composite-to-metal bonded structures and the temperature effect on their performance. This is of major importance in hybrid structures since the difference in coefficients of thermal expansion between the metal skin and the composite stiffener induces high residual thermal stresses at the adhesive bondline, which can compromise the integrity of the bonded joint.

In this research the aim is to study the temperature effect on the structural integrity on composite-to-metal bonded structures, namely skin-to-stiffener joints. Static SPOT were performed using two different adhesives and in a wide temperature range - from $-55^{\circ} \mathrm{C}$ up to $+100{ }^{\circ} \mathrm{C}$. This research is the follow up of a previous study performed by the 
authors on the comparison between metal-to-metal and composite-to-metal skin-to-stiffener bonded joints (Teixeira de Freitas and Sinke, 2015a).

\section{MATERIALS AND SPECIMENS}

Stiffener pull-off test specimens were manufactured by bonding a Carbon Fibre Reinforced Polymer (CFRP) stiffener to the Fiber Metal Laminate (FML) skin.

\subsection{Materials}

The Fiber Metal Laminate (FML) skin was Glare 5-3/2-0.3, which consists of three 2024-T3 aluminium alloy layers $0.3 \mathrm{~mm}$ thick, bonded together with glass prepregs S2-glass/FM-94 with the layup $\left[0^{\circ} / 90^{\circ} / 90^{\circ} / 0^{\circ}\right]$. The skin layup is therefore $\left[\mathrm{Al} /\left[0^{\circ} / 90^{\circ} / 90^{\circ} / 0^{\circ}\right] / A l /\left[0^{\circ} / 90^{\circ} / 90^{\circ} / 0^{\circ}\right] / A l\right]$. The outer faces of the skin are Aluminium layers (metal). The skin was cured in the autoclave according to the standard procedure for Glare (4 bars, 60 min at $120^{\circ} \mathrm{C}$ ). The aluminium surfaces were pre-treated with chromic acid anodizing and primed with BR 127 (Cytec Engineered Materials, Tempe, Arizona, USA).

The CFRP stiffeners were prepared from unidirectional pre-preg consisting of HexPly 8552 epoxy matrix in combination with AS4 carbon fiber (Hexcel Corporation, Stamford, Connecticut, USA). The CFRP stiffener was an inverted T-shape stiffener. The web and flange of the CFRP foot have the same layup $\left[+45^{\circ} / 0^{\circ} / 90^{\circ} /-45^{\circ}\right]_{S}$. The noodle region was filled with $0^{\circ}$ fibers. The stiffener was cured at $180^{\circ} \mathrm{C}$ for $120 \mathrm{~min}$ in the autoclave. Prior to bonding, the CFRPstiffener-foot surfaces were abraded with sand paper and then wiped clean with an acetone-soaked cloth. Figure 1 shows the configuration of the CFRP stiffener.

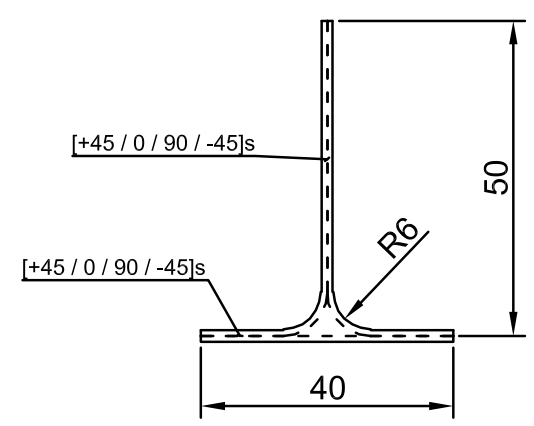

Figure 1. CFRP Stiffeners' configuration (dimension in $\mathrm{mm}$ ).

Two structural adhesives were used - AF 163-2K.06 (3M, Minnesota, USA) and EA9696.060 PSF K (Henkel, Düsseldorf, Germany). Both are epoxy film adhesives with a curing temperature of $120^{\circ} \mathrm{C}$ for $90 \mathrm{~min}$ in the autoclave. These two adhesives had the best performance from screening tests performed on ten different adhesives, in terms of good adhesion to metals and to composites, and in terms of apparent average shear strength (Teixeira de Freitas and Sinke, 2015b). AF 163-2 has been on the market for many years and it is being used for metal bonding and, more recently, for composite bonding. EA 9696 is especially tailored for high toughness applications. This last feature can be of major importance for the hybrid joint, since we are joining materials with different coefficient of thermal expansion.

Tables 1 and 2 show the mechanical properties taken from literature and from the Technical Data Sheet (TDS) of the materials used. The Glass transition temperature of the adhesives AF 163-2 and EA 9696 is approximately $+110^{\circ} \mathrm{C}$ and of the epoxy resin FM94 of the glass prepeg is approximately $+100{ }^{\circ} \mathrm{C}$.

Table 1. Mechanical properties of the isotropic materials used.

\begin{tabular}{lllll}
\hline & $E(\mathrm{MPa})$ & $\sigma_{y}(\mathrm{MPa})$ & $\sigma_{\max }(\mathrm{MPa})$ & $\nu(-)$ \\
\hline Al 2024-T3 & 72400 & 347 & 420 & 0.33 \\
AF 163-2 (TDS) & 1110 & - & 48.3 & 0.34 \\
EA 9696 (TDS) & 2082 & - & 45.9 & 0.34 \\
\hline
\end{tabular}


Table 2. Mechanical properties of the orthotropic materials used.

\begin{tabular}{lllll}
\hline & $E_{1}(\mathrm{MPa})$ & $E_{2}(\mathrm{MPa})$ & $\nu_{12}(-)$ & $\nu_{21}(-)$ \\
\hline S2-glass/FM-94 & 48900 & 5500 & 0.33 & 0.0371 \\
HexPly-8552/AS4 (TDS) & 131000 & 9240 & 0.302 & 0.029 \\
\hline
\end{tabular}

\subsection{Specimens}

The base line of the Pull-off specimens is a Glare skin adhesively bonded to a CFRP stiffener at mid length. Two series of specimens were manufactured, one using AF 163-2 and another using EA9696. The specimens were $100 \mathrm{~mm}$ wide and $200 \mathrm{~mm}$ long.

\section{EXPERIMENTAL PROCEDURE}

\subsection{Adhesive material testing}

Tensile tests were performed on the adhesives bulk material at three environmental temperatures: $-55^{\circ} \mathrm{C}$, room temperature $\left(+22^{\circ} \mathrm{C}\right)$ and $+100{ }^{\circ} \mathrm{C}$. Adhesive films without carrier were used to manufacture dog-bone shaped specimens - AF163-2U.015WT and EA9696.060 NW. The experimental procedure and specimens dimensions were in accordance with the standard ASTM-D638 (2008). A temperature chamber was coupled to the testing machine to test under different temperatures. The tests were carried out at displacement control with a testing speed of $5 \mathrm{~mm} / \mathrm{min}$ using a testing machine with maximum test load of $10 \mathrm{kN}$. Five specimens were tested in each test series. A mechanical extensometer was used to measure the specimens' elongation.

\subsection{Stiffener pull-off tests}

The pull-off test setup is shown in Figure 2. The clamping of the skin was guaranteed by two steel plates on each support, connected to the skin by bolts. A tensile load was applied vertically to the stiffener web (P - see Fig. 2) using a clamp. The skin span was kept fixed to all test series and equal to $100 \mathrm{~mm}$.

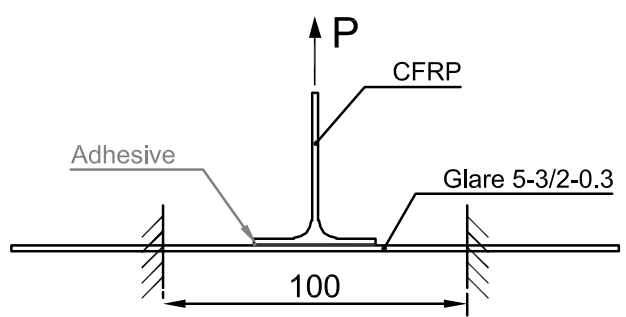

Figure 2. Experimental setup (dimension in $\mathrm{mm}$ ).

The quasi-static tests were performed at three environmental temperatures: $-55^{\circ} \mathrm{C}$, room temperature $\left(+22^{\circ} \mathrm{C}\right)$ and $+100^{\circ} \mathrm{C}$. A temperature chamber was coupled to the testing machine in order to test at high and low temperatures. The tests were carried out at displacement control with a testing speed of $3 \mathrm{~mm} / \mathrm{min}$. The loads and piston displacement were recorded during testing. The tests were performed until the stiffener was completely detached from the skin. Typically, three specimens were tested at the same test conditions.

\section{RESULTS AND DISCUSSION}

\subsection{Adhesive material testing}

Figure 3 shows representative stress-strain curves of the adhesives AF163-2 and EA9696. Temperature affects significantly the adhesives behaviour. Both adhesives show brittle behaviour at $-55^{\circ} \mathrm{C}$ and ductile behaviour at $+100{ }^{\circ} \mathrm{C}$.

Table 3 lists the tensile mechanical properties for both adhesives at the three temperatures tested - Young's modulus $E$, tensile strength $\sigma_{\max }$ and tensile failure strain $\epsilon_{\max }$.

EA9696 behaviour is more ductility than AF163-2 at room temperature and $+100^{\circ} \mathrm{C}$, without any decrement of the tensile strength. At $-55{ }^{\circ} \mathrm{C}$ both adhesives show brittle behaviour but AF163-3 tensile strength is $45 \%$ higher than EA9696.

At room temperature, the results of the tensile tests are in agreement with the values obtained from literature (see Table 1) with the exception of the Young's modulus of AF163-2. The value from the tensile tests is $80 \%$ higher than the 
one given at the Technical Data Sheet (tests - $2043 \mathrm{MPa}$ and TDS - $1110 \mathrm{MPa}$ ). Nevertheless, the tests results have a significant confidence since within the 5 specimens tested only $6 \%$ of standard deviation was observed from the average value $2043 \mathrm{MPa}$.

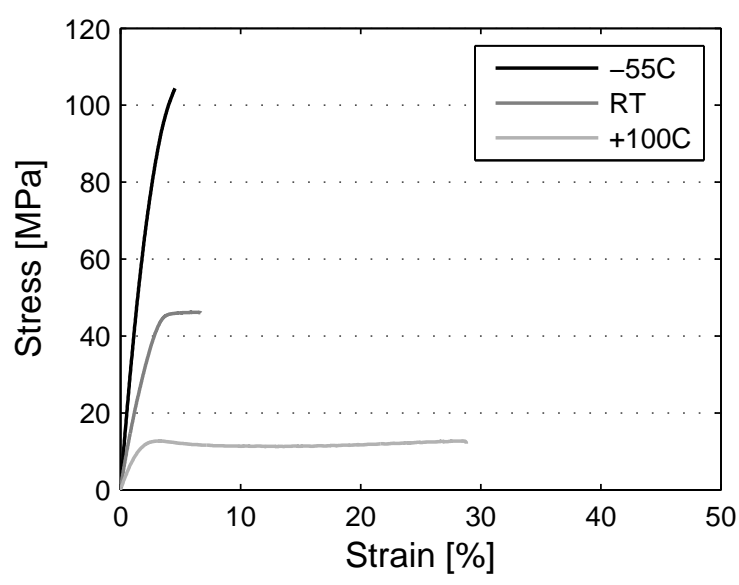

(a)

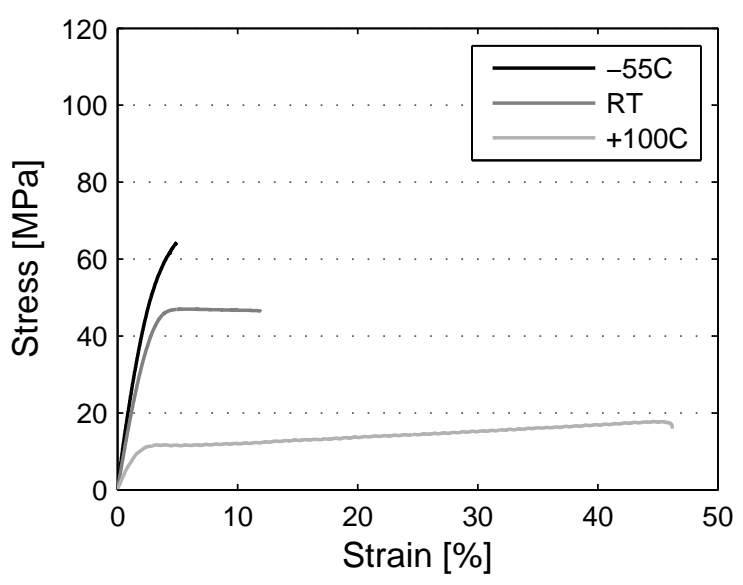

(b)

Figure 3. Tensile stress-strain curves of adhesive (a) AF163-2 and (b) EA9696.

Table 3. Tensile mechanical properties of AF163-3 and EA9696 (Average \pm standard deviation).

\begin{tabular}{lllllll}
\hline & AF 163-2 & & EA9696 & \\
& $E(\mathrm{MPa})$ & $\sigma_{\max }(\mathrm{MPa})$ & $\epsilon_{\max }(\%)$ & $E(\mathrm{MPa})$ & $\sigma_{\max }(\mathrm{MPa})$ & $\epsilon_{\max }(\%)$ \\
\hline$-55{ }^{\circ} \mathrm{C}$ & $3085 \pm 14 \%$ & $102.90 \pm 6 \%$ & $4.81 \pm 14 \%$ & $2505 \pm 4 \%$ & $70.50 \pm 7 \%$ & $4.49 \pm 14 \%$ \\
$\mathrm{RT}$ & $2043 \pm 6 \%$ & $45.70 \pm 3 \%$ & $5.38 \pm 27 \%$ & $2019 \pm 4 \%$ & $47.83 \pm 2 \%$ & $11.51 \pm 14 \%$ \\
$+100{ }^{\circ} \mathrm{C}$ & $683 \pm 17 \%$ & $12.97 \pm 8 \%$ & $29.45 \pm 30 \%$ & $999 \pm 5 \%$ & $19.85 \pm 9 \%$ & $56.79 \pm 16 \%$ \\
\hline
\end{tabular}

\subsection{Stiffener pull-off tests}

Typical load-displacement curves at the tested three temperatures for the two adhesive are shown in Figure 4 . Figure 5 shows pictures of a typical damage initiation, progression and final fracture surface. The damage was very similar within the temperature range tested and for the two adhesives. The damage typically initiated at the noodle region of the CFRP stiffener, as shown in Fig. 5(a). The damage initiation corresponds to the maximum pull-off load registered. This damage initiation is accompanied by a sudden drop of the load, from which the damage propagates at much lower load levels, approximately $40 \%$ of maximum load. The initial crack propagated through the stiffener foot plies and through the web plies, as shown in Fig. 5(b). The final failure occurs when the composite stiffener is completely detached from the skin. A typical final fracture surface is shown in Fig. 5(c). The final failure mode is clearly interlaminar and intralaminar failure of the composite stiffener. Furthermore, from the fracture surface and from the damage propagation, one can also observe that the crack tends to propagate mainly through the symmetry plane of the layup of the stiffener $\left[+45^{\circ} / 0^{\circ} / 90^{\circ} /-45^{\circ}\right]_{S}$, meaning in the $45^{\circ}$ layer and at the $45^{\circ}$ and $90^{\circ}$ interface.

There was no failure observed in the adhesive bondline for any of the specimens tested. Even when the thermal residual stresses are maximum at the bondline (at $-55^{\circ} \mathrm{C}$ ), damage still occurs in the composite stiffener and not in the adhesive. This results show that both adhesives AF 163 and EA9696 are ductile enough to withstand the thermal residual stresses induced at the bondline due to considerably different coefficients of thermal expansion between the CFRP stiffener and the Glare skin. It can be considered that these residual stresses are zero at the curing temperature of the adhesive (at $+120^{\circ} \mathrm{C}$ ) and have their maximum value at $-55^{\circ} \mathrm{C}$ (largest temperature variation).

Table 4 lists the test results including flexural stiffness $K$, maximum load $P_{\max }$ and displacement at maximum load $\delta_{P_{\max }}$ for the six test series ( 3 temperatures $\mathrm{x} 2$ adhesives). For better interpretation of these results, the results for flexural stiffness $K$ and maximum load $P_{\max }$ are also shown in a bar chart in Figure 6.

The maximum load and the correspondent displacement significantly increase with temperature. At $+100^{\circ} \mathrm{C}$ the maximum load increases approximately $15 \%$ to $30 \%$ when compared to RT. For the displacement the difference is even greater with more than twice the value for $+100{ }^{\circ} \mathrm{C}$ when compared to RT. At $-55^{\circ} \mathrm{C}$ the maximum load and correspondent displacement decrease approximately $50 \%$ to $60 \%$ when compared to RT.

The flexural stiffness shows a different behaviour. At $-55^{\circ} \mathrm{C}$ and RT, the flexural stiffness are practically the same. However, at $+100^{\circ} \mathrm{C}$, this value decreases almost $40 \%$ when compared to RT, as shown in Fig.6(b). The flexural stiffness 


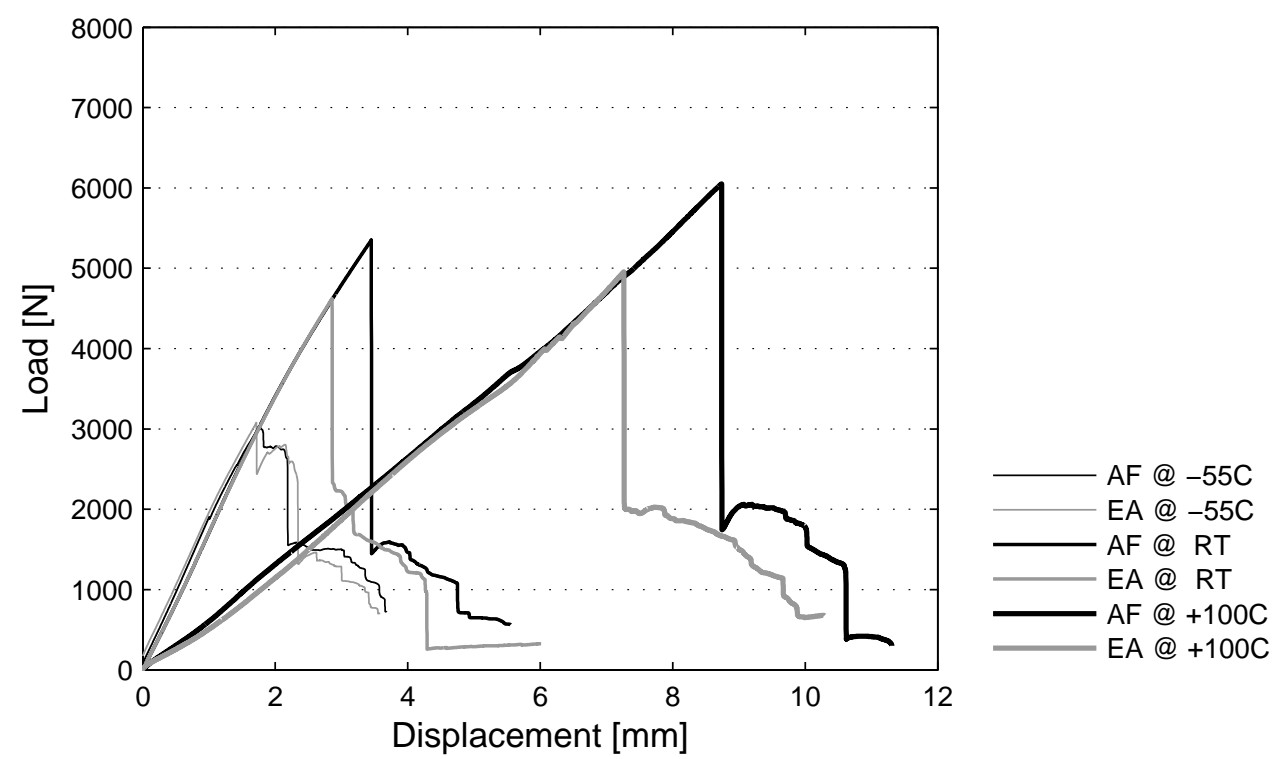

Figure 4. Typical load-displacement curves at the three temperatures tested for the two adhesives.

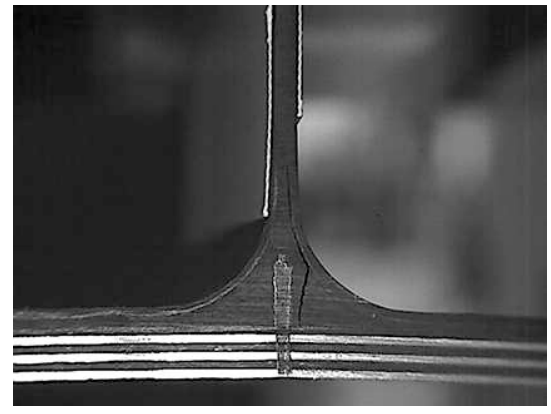

(a)

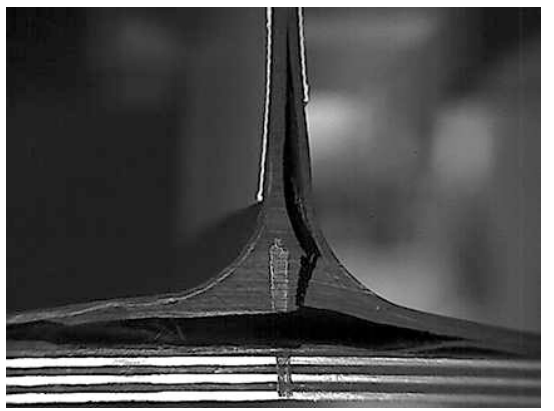

(b)

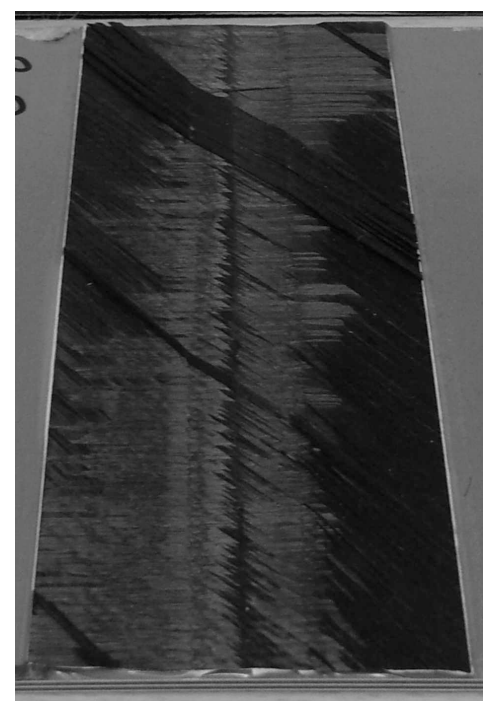

(c)

Figure 5. Typical quasi-static failure stages (a) damage initiation at the central noddle of the composite stiffener correspondent to maximum load, (b) damage progression and (c) final failure mode when detached (view of the delaminated stiffener foot).

of the tests corresponds to the flexural stiffness of the Glare skin. It has no influence of the adhesive material (same results independent of the adhesive used). The reason behind the significant drop of flexural stiffness at $+100^{\circ} \mathrm{C}$, has to do with the fact that the resin of the glass prepreg layer has a glass transition temperature close to $+100^{\circ} \mathrm{C}$. Beyond the glass transition temperature, the stiffness of the epoxy resin decreases significantly.

The increase of failure load with temperature has probably to do with the change of the mechanical behaviour of the composite stiffener with temperature, since that is where the failure occurs. As the behaviour of carbon fibers are not significantly affected by temperature within the range tested, the change in the mechanical behaviour of the composite stiffener must be caused by the temperature effect on the composite resin. The composite resins are epoxies, therefore the tensile tests performed on the adhesives, which are also epoxies, can give an indication of the temperature effect on those materials. As observed in Fig.3, epoxies show a brittle behaviour at low temperatures and ductile behaviour at high temperatures. The increase of ductiliy of the epoxy resin in the composite results in a decrease of stress concentration at the stiffener. The decrease of stress severity postpones the damage initiation at the central noodle and increases the maximum load and the corresponding displacement.

The significant decrease of flexural stiffness of the skin at $100{ }^{\circ} \mathrm{C}$ also contributes to a better load distribution in the joint, contributing for less stress concentration and higher load capacitites than at lower temperatures. 
No influence of the adhesive AF163 and EA 9696 is observed neither in the maximum load values nor in the flexural stiffeness.

Table 4. Stiffener pull-off test results: stiffness $K$, maximum load $P_{\max }$ and displacement at maximum load $\delta_{P_{\max }}$ (average \pm standard deviation).

\begin{tabular}{lllllll}
\hline & AF 163-2 & & EA9696 \\
& $K(\mathrm{~N} / \mathrm{mm})$ & $P_{\max }(\mathrm{N})$ & $\delta_{P_{\max }}(\mathrm{mm})$ & $K(\mathrm{~N} / \mathrm{mm})$ & $P_{\max }(\mathrm{N})$ & $\delta_{P_{\max }}(\mathrm{mm})$ \\
\hline$-55{ }^{\circ} \mathrm{C}$ & $1827 \pm 6 \%$ & $2769 \pm 8 \%$ & $1.7 \pm 9 \%$ & $1730 \pm 3 \%$ & $2867 \pm 9 \%$ & $1.8 \pm 5 \%$ \\
$\mathrm{RT}$ & $1727 \pm 2 \%$ & $5249 \pm 20 \%$ & $3.3 \pm 22 \%$ & $1745 \pm 2 \%$ & $4386 \pm 16 \%$ & $2.7 \pm 16 \%$ \\
$+100{ }^{\circ} \mathrm{C}$ & $689 \pm 5 \%$ & $6963 \pm 12 \%$ & $8.2 \pm 9 \%$ & $709 \pm 9 \%$ & $5058 \pm 6 \%$ & $7.3 \pm 6 \%$ \\
\hline
\end{tabular}

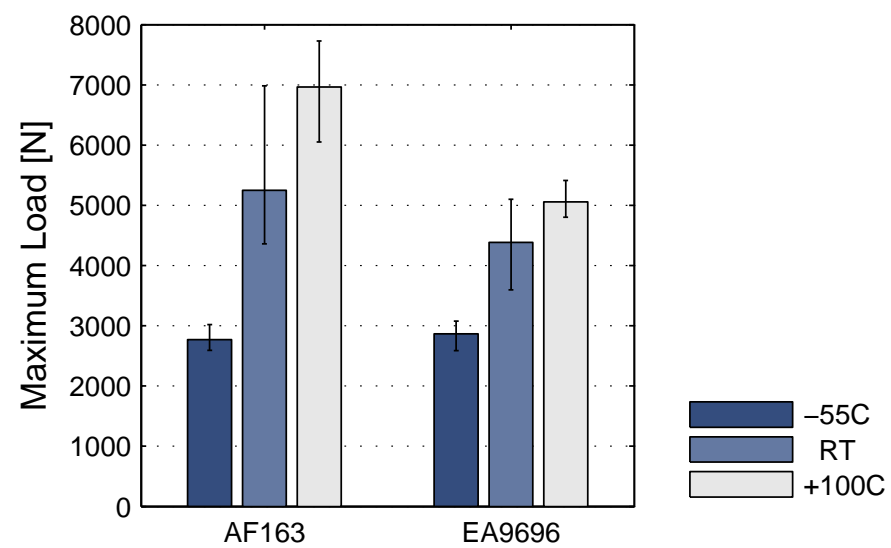

(a)

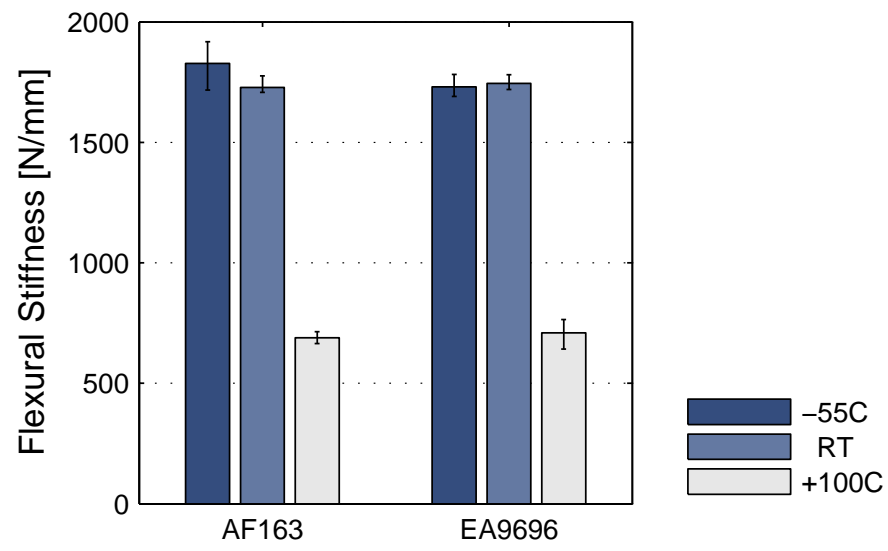

(b)

Figure 6. Maximum load (a) and flexural stiffness (b) at the three temperatures tested for the two adhesives. 


\section{CONCLUSIONS}

Stiffener pull-off tests were performed on adhesively bonded Glare skin to composite stiffener. Tests were performed at three environmental temperatures $-55^{\circ} \mathrm{C}$, RT and $+100^{\circ} \mathrm{C}$, and using two adhesives AF163-2 and EA9696. The aim was to study the temperature effect on the static behaviour of the composite-to-metal bonded structure.

From the analysis of the tests, the following conclusions can be drawn:

- The damage sequence is very similar within the temperature range tested and for the two adhesives. The damage initiates at the central noodle of the composite stiffener. The initial damage corresponds with the maximum load. Unstable delamination then propagates from the noodle to the tip of the stiffener foot at much lower load level (approximately $40 \%$ of maximum load).

- The final failure occurs when the composite stiffener is detached from the skin. The failure mode is interlaminar and intralaminar failure of the composite, mainly in the stiffener foot plies.

- Despite the expected high residual thermal stresses at the adhesive bondline, namely at $-55^{\circ} \mathrm{C}$, no damage has been observed in the adhesives within the tested temperature range.

- The stiffness of the composite-to-metal bonded structure is determined by the glare skin flexural stiffness. A significant stiffness drop is observed when the testing temperature is close to the glass transition temperature of the epoxy resin of glare's glass-prepreg.

- The maximum load capacity of the joint increases with temperature due to an increase on the ductility of the composite stiffener and glare skin. This allows for lower stress concentrations at "hot-spots", such as the central noodle, allowing for higher maximum loads.

- This research identifies that the composite stiffener is the weakest link of the composite-to-metal bonded structures in study, and not at the adhesive bondline. This holds for static loading in a wide temperature range.

\section{ACKNOWLEDGEMENTS}

This research was supported by Materials innovation institute (M2i) and Fokker Aerostructures.

\section{REFERENCES}

ASTM-D638, 2008. "D638-08: Standard Test Method for Tensile Properties of Plastics".

Greenhalgh, E., Lewis, A., Bowen, R. and Grassi, M., 2006. "Evaluation of toughening concepts at structural features in CFRP-Part I: Stiffener pull-off”. Composites Part A: Applied Science and Manufacturing, Vol. 37, No. 10, pp. 1521-1535. doi:10.1016/j.compositesa.2005.11.009.

Khoshravan, M. and Asgari Mehrabadi, F., 2012. "Fracture analysis in adhesive composite material/aluminum joints under mode-I loading; experimental and numerical approaches". International Journal of Adhesion and Adhesives, Vol. 39, pp. 8-14. doi:10.1016/j.ijadhadh.2012.06.005.

Li, J., 2002. "Pull-off tests and analysis of composite skin and frame T-joint". In 17th Annual Technical Conference of the American Society for Composites.

Seong, M., Kim, T., Nguyen, K., Kweon, J. and Choi, J., 2008. "A parametric study on the failure of bonded single-lap joints of carbon composite and aluminum". Composite Structures, Vol. 86, No. 1-3, pp. 135-145. doi: 10.1016/j.compstruct.2008.03.026.

Teixeira de Freitas, S. and Sinke, J., 2014. “Adhesion Properties of Bonded Composite-to-Aluminium Joints Using Peel Tests”. The Journal of Adhesion, Vol. 90, No. 5-6, pp. 511-525. doi:10.1080/00218464.2013.850424.

Teixeira de Freitas, S. and Sinke, J., 2015a. "Failure analysis of adhesively-bonded skin-to-stiffener joints: Metal-metal vs. composite-metal”. Engineering Failure Analysis. doi:10.1016/j.engfailanal.2015.05.023.

Teixeira de Freitas, S. and Sinke, J., 2015b. "Test method to assess interface adhesion in composite bonding". Applied Adhesion Science, Vol. 3, No. 1, pp. 1-13.

\section{RESPONSIBILITY NOTICE}

The authors are the only responsible for the printed material included in this paper. 